\title{
Catálogo Colectivo de las Colecciones de Mapas, Planos y Dibujos de los Archivos Estatales: nuevos proyectos en el Archivo General de Simancas
}

The Spanish National Archives Collective Catalogue of Maps, Plans and Drawings: new projects at the Simancas General Archive

\author{
Jaime SAINZ GUERRA \\ Archivo General de Simancas, C/ Miravete n. 8, Simancas (Valladolid, España), jaime.sainz@mced.es
}

\begin{abstract}
Resumen
El Catálogo Colectivo de las Colecciones de Mapas, Planos y Dibujos de los Archivos Estatales recoge material cartográfico, grafico y tridimensional existentes en dichos archivos. En este proyecto se ha trabajado sobre la colección del Archivo General de Simancas. En esta primera etapa, se han desarrollado la metodología para la creación de la nueva base de datos a partir de la ya existente, los manuales de procedimiento, el mapeo y volcado de datos, el desarrollo de un repositorio digital OAI-PMH y la creación del servidor web. El proyecto ha dado lugar a una mayor "visibilidad" de estos fondos de archivo, acceso directo a la información desde los buscadores y la posibilidad de participar en proyectos cooperativos (Europeana, Hispana...). Los nuevos retos de nuestra cartoteca digital se orientan hacia una mejor visualización de la información geográfica, por lo que nos hemos planteado la georreferenciación de la colección cartográfica y la posible difusión de nuestros fondos en los catálogos de cartografía histórica como los utilizados en las Infraestructuras de Datos Espaciales.
\end{abstract}

Palabras clave: Colección de Mapas Planos y Dibujos de los Archivos Estales. Archivo General de Simancas. Georreferenciación.

\section{Creación del Catálogo Colectivo}

\subsection{Primeros pasos}

En origen, el proyecto pretendía la creación de un catálogo colectivo que aglutinara las colecciones de Mapas, Planos y Dibujos pertenecientes a los Archivos Estatales.La base del proyecto iba a ser el establecimiento de un sitio o página web independiente desde la que se accedería al portal del catálogo colectivo. Los metadatos estarían ubicados dentro del "Catalogo Colectivo de Bibliotecas de Archivo", como una sección más, compartiendo las autoridades (1), pero visualmente autónomo. De este modo se lograba utilizar un gestor de bases de datos de

\begin{abstract}
The State Archives Maps, Plans and Drawings collective catalogue includes cartographic, graphic and three-dimensional materials existing in these archives. A project on the collection of the Archivo General de Simancas is described. In its first stage of development, the methodology for the creation of the new data base from what already exists, procedures manuals, data mapping and loading, OAI-PMH digital repository development and the creation of the web server have been finalized. The project has resulted in a greater "visibility" of these holdings, direct access to the information from search engines and the possibility of participating in cooperative projects (Europeana, Hispania...). The new challenge for our digital map library is achieving a better visualization of the geographic information, so we have started the georeferenciation of the cartographic collection and studied the possible dissemination of our holdings throughout the historical cartographic catalogues that use spatial data infrastructures.
\end{abstract}

Keywords: Spanish National Archives. Collective Catalogue of Maps, Plans and Drawings (Spain). Archivo General de Simancas (Spain). Georeferencing.

calidad, pero con un acceso independiente, lo que evitaría la confusión entre los fondos de las bibliotecas y los archivos, facilitando su comprensión.

Este elemento que se consideró prioritario a la hora de gestionar el catálogo colectivo no pudo realizarse debido a restricciones presupuestarias, por lo que en lugar de desarrollarse en una web independiente, se utilizó, en su lugar, el servidor web ya existente del Catálogo Colectivo de Bibliotecas de Archivo. No se pudo lograr, por lo tanto, una de las metas del proyecto, que era describir una colección de archivo con un software de bibliotecas, pero con una presentación independiente. Se perdió una de las bazas 
con la que jugaba el catálogo que era la de la autonomía, la de utilizar un sistema pero estar separado de él.

Otro de los elementos que conllevaba el proyecto era la utilización como estructura de datos del MARC 21 (2) y como norma de contenido las ISBD (International Standard Bibliographic Description), las Reglas de catalogación (2000) españolas y las AACR2 (Anglo-American Cataloguing Rules).

La normalización proporcionada por el proyecto, que finalmente se ha llevado a cabo, ha dado lugar a una mayor "visibilidad" de los fondos, ya que permite el acceso directo desde los buscadores a la información. Posibilita además la participación en proyectos cooperativos (Catálogo Colectivo del Patrimonio Bibliográfico), permitiendo la difusión de nuestros fondos en los catálogos gestionados mediante tecnología CSW de OGC, Europeana, Apnet, Hispana del Ministerio de Cultura... y en cualquier otro tipo de repositorio basado en tecnología OAI-PMH (Open Archives Initiative Protocol for Metadata Harvesting).

\subsection{La base del proyecto:}

El Archivo General de Simancas

La Colección de Mapas, Planos y Dibujos se ha formado por el desglose de material cartográfico, gráfico, tridimensional y textual, procedente de la documentación de los fondos existentes en el Archivo General de Simancas (AGS).

A comienzos de 2010 la Colección de Mapas, Planos y Dibujos (7624 registros) estaba completamente automatizada. Utilizaba como estructura de datos el formato Ibermarc y como norma de contenido las ISBD, AACR2 y Reglas de catalogación (2000) españolas. También estaba digitalizado el $100 \%$ de la colección.

Sus fondos no se habían volcado a la red PARES (Portal de Archivos Españoles) (3) ya que utilizaban estructura de datos y normas de contenido completamente diferentes. En los Archivos Estatales no existían, ni existen actualmente, normas de contenido ni formatos de datos homogéneos para la descripción de materiales especiales.

La base del proyecto fue volcar toda la información existente en un catalogo colectivo estructurado siguiendo el formato MARC 21. No todos los centros que iban a formar parte de este proyecto se encontraban en la misma situación. Por ahora, sólo se han volcado los registros del Archivo General de Simancas, que ya se hallaban en formato Ibermarc, razón por la cual su integración en éste catálogo ha sido mucho más sencilla.

\section{Etapas del proyecto}

\subsection{Manuales de procedimiento}

Antes de comenzar con el mapeo y el volcado había que detallar la norma de contenido y precisar el formato de datos. Los estándares de contenido de datos son las normas que establecen cómo se completa un determinado campo de datos. Tanto la ISAD (Norma Internacional General de. Descripción Archivística) como las ISBD son normas de contenido. Sus elementos se pueden utilizar para la descripción, aunque en ellas no se incluyen pautas para la creación de los puntos de acceso a la descripción.

El desarrollo de unas normas de contenido, dio lugar en Estados Unidos a las Describing archives: a content standard (DACS), en el campo de los archivos y las AACR2 en el campo de las bibliotecas. Las DACS recomiendan la utilización de normas especializadas para cada tipo de material, utilizando las AACR2 como norma general de contenido. En su introducción (Society of American Archivists, 2004) se especifica:

Las DACS no contienen reglas específicas para la descripción de materiales especiales, grabaciones de sonido, mapas, fotografías... Las normas para la descripción de tales materiales están creadas y mantenidas por otros grupos en las comunidades bibliotecarias y archivísticas, y reproducir estas reglas o intentar suplantarlas aquí, nos parecería presuntuoso y su mantenimiento una pesadilla. Los archiveros que necesiten tales reglas especializadas deberían consultar las normas específicas...

Coincidiendo con este criterio se utilizaron para describir el material cartográfico y gráfico las normas de contenido bibliotecarias: ISBD, las AACR2 y las Reglas de catalogación (2000). El formato de datos es la codificación de la información en formato electrónico. MARC 21 es nuestro formato de datos.

En los manuales de procedimiento constan los campos, etiquetado y dolarizados que hay que rellenar en el formato MARC 21. Se detallan las normas de aplicación de cada campo y problemas con los que nos podemos encontrar en la descripción. El primer manual que se ha realizado ha sido el de material cartográfico, debido a que conforma más del $70 \%$ de la colección. Además habrá que realizar otros para el material gráfico (dibujos y grabados) y para el material en tres dimensiones existente en nuestros centros (telas, monedas...).

\subsection{Mapeos a MARC 21}

Después de conocer con exactitud qué campos se van a rellenar en la estructura de datos y la norma de contenido que se va a utilizar, se tenía 
que realizar un mapeo de los campos de las antiguas bases de datos a la nueva base del catálogo colectivo. El único que se realizó es el del formato Ibermarc a MARC 21. Este mapeo era fundamental para que el volcado a la nueva base se realizara correctamente, ya que la antigua (Biblio-3000) estaba en Ibermarc. Se habilitaron los nuevos campos y etiquetas que aparecen en MARC 21 para materiales especiales.

\subsection{Creación del servidor web}

El catálogo se instaló en la base de datos Digibib que actualmente soporta el Catálogo colectivo de la red de Bibliotecas del Centro de Información Documental de Archivos (CIDA) y de los Archivos Estatales. El único nexo de unión entre las dos bases es el catálogo de autoridades que es compartido.

\subsection{Volcado de las distintas bases de datos}

Una vez realizado el manual de procedimiento y el mapeo, se procedió al volcado. El volcado y las pasarelas, para el caso de Simancas, las desarrolló la empresa Digibis, encargada también del desarrollo de la base de datos y del servidor web.

\subsection{Control de calidad y corrección de errores}

Después del trabajo de migración se realizó una tarea de control de calidad y de corrección de errores, ya que ninguna pasarela entre dos sistemas es perfecta.

\subsection{Enlace de la digitalización}

Después de crear el catálogo colectivo se enlazaron los registros digitalizados. El archivo se encargó de suministrar a la empresa desarrolladora del proyecto Digibis las imágenes digitalizadas de la totalidad de la colección, y ellos se encargaron de introducirlas en el repositorio digital.

\section{Repositorio digital OAI-PMH}

Con la nueva versión de Digibis 6.0 el sistema permite la gestión de repositorios digitales. Permite vía web el acceso de los recolectores que proporcionan los servicios basados en el protocolo OAI-PMH. El recolector está gestionado por un proveedor de servicio que tiene como misión recolectar datos de los repositorios.

El repositorio está gestionado por un proveedor de datos que expone sus metadatos a los recolectores, aplicación cliente que tramita las peticiones OAI.
El protocolo OAI-PMH soporta múltiples formatos de metadatos. Los repositorios difunden sus datos mediante ficheros XML, y el formato mínimo de exportación es Dublin Core.

Los repositorios están divididos en "sets", unas divisiones en secciones dentro del propio repositorio creadas opcionalmente para facilitar una búsqueda selectiva de los registros. Los sets son simples listas o estructuras jerárquicas. En nuestro caso, del catálogo colectivo dependen colecciones; y, dentro de cada una de ellas, pueden aparecer diferentes divisiones. Un cliente puede pedir que se recupere un set específico que le permite recuperar los registros pertenecientes a una determinada clase — como se da, en nuestro repositorio, con el material cartográfico, el material gráfico, el material tridimensional y el textual.

Los recolectores son quienes proveen el servicio de catálogo al público y deben recolectar los metadatos de los repositorios. En nuestro caso Hispana es un recolector, que, además, agrega contenidos para otros recolectores tales como Europeana, recolector de recolectores.

\section{Servidor web : Colección de Mapas, Planos y Dibujos del Archivo General de Simancas}

El Catálogo Colectivo de la Colección de Mapas, Planos y Dibujos de los Archivos Estatales está ubicado como una sección dentro del catálogo colectivo de la Red de Bibliotecas de los Archivos Estatales (s. a.). Nada más abrir la página aparece la presentación de la única colección que por ahora se encuentra disponible, que es la del Archivo General de Simancas (Figura 1). En el futuro se añadirán al catálogo el resto de las colecciones de Mapas y Planos.

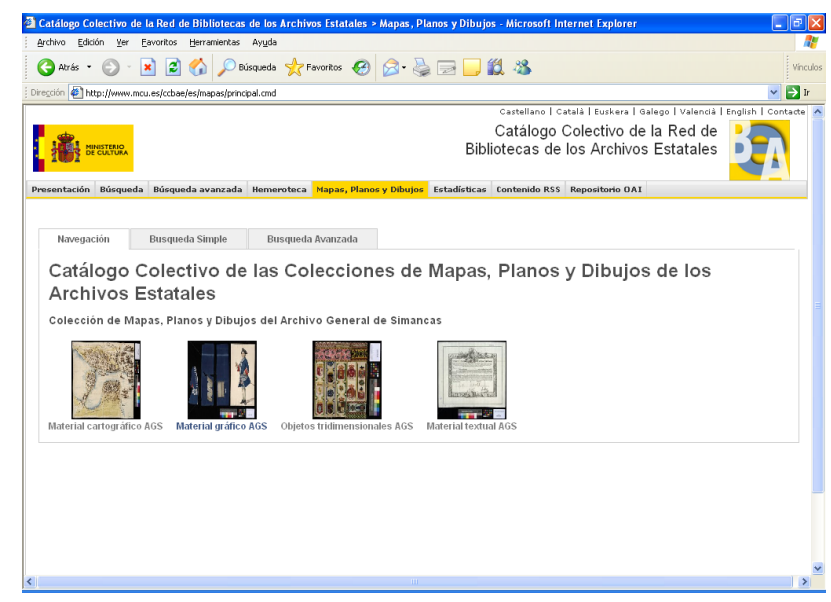

Figura 1. Pantalla principal del catálogo 
En ésta primera página de presentación se ha estructurado la colección de Simancas por tipos de material (cartográfico, gráfico, tridimensional y textual) identificados por una miniatura (ejemplo de cada material). Accediendo a cada uno de ellos, el sistema nos permite hojear cada uno de los registros que pertenecen a estas subsecciones.

En la presentación de "Navegación" se puede acceder a la totalidad de los registros de la base de datos, lo que permite hojear las descripciones, proporcionando al usuario una visión más de conjunto de la Colección (Figura 2).

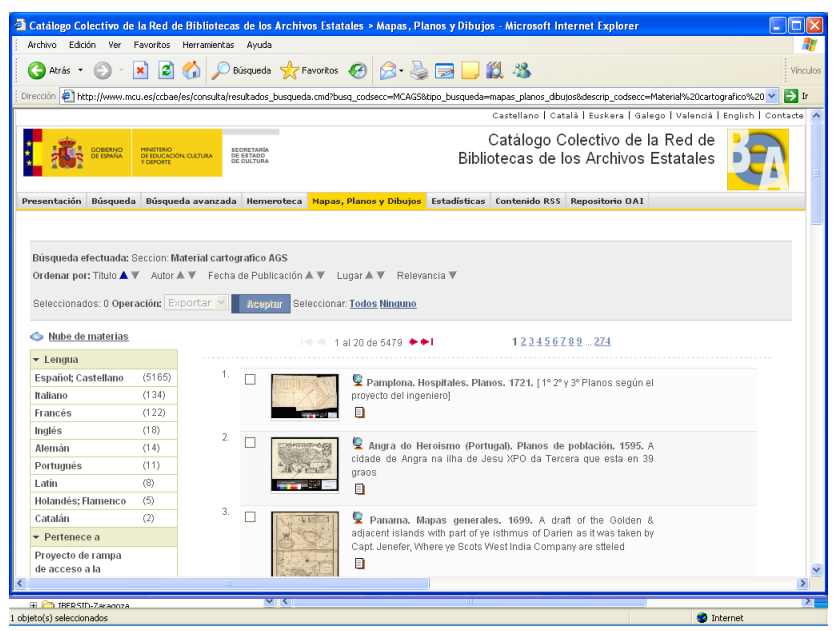

Figura 2. Visualización de los registros cartográficos

\subsection{Búsqueda simple}

Permite al usuario buscar en la base de datos en aquellos campos que se han identificado como principales (autor, titulo, lugar geográfico, materia, lengua, año de publicación, notas y tipo de documento). También el sistema da la posibilidad de buscar por cualquier campo.

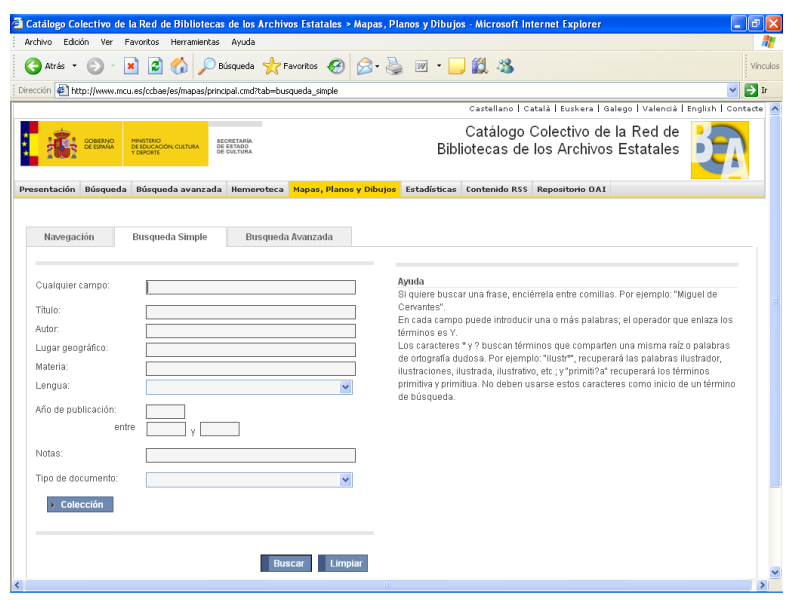

Figura 3. Pantalla de búsqueda simple
En los campos lengua y tipo de documento el sistema abre un desplegable para la elección del tipo (Figura 3).

\subsection{Búsqueda avanzada}

En la pestaña de búsqueda avanzada la página web aumenta el número de campos "buscables": lugar de publicación, signatura, signatura de procedencia, editor, notas, escala, genero/forma.

Estos son campos más especializados y directamente creados para que los investigadores más especializados puedan acceder a la documentación relacionada -documentación de donde se ha desglosado el material cartográfico por necesidades de conservación- (Figura 4).

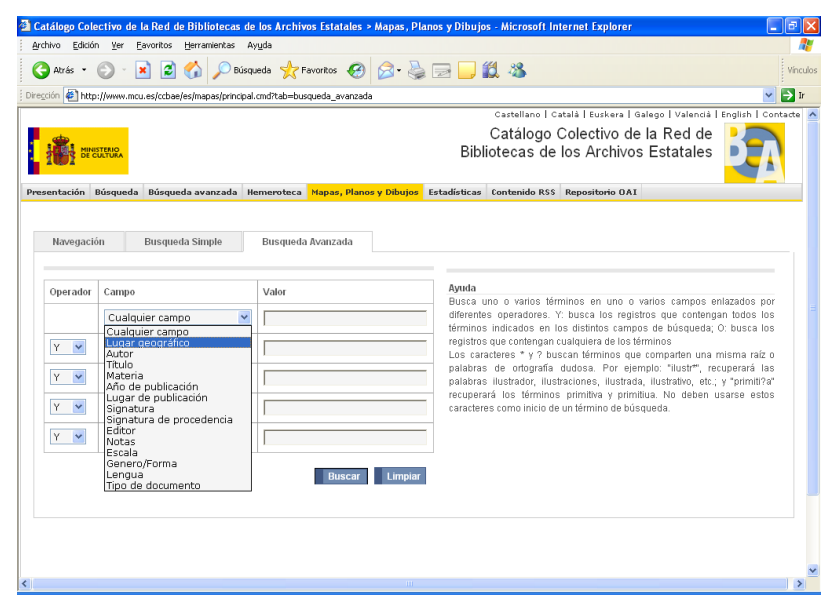

Figura 4. Pantalla de búsqueda avanzada

No aparece el campo Sección -denominación que da el sistema a cada una de las colecciones-, porque por ahora sólo aparece la del Archivo General de Simancas. En el momento en que se vuelque la documentación de algún otro archivo, aparecerá para así poder buscar por colecciones.

\subsection{Ordenación de los registros}

Los registros aparecen ordenados por el título, pero pueden clasificarse también por autor, fecha de publicación, lugar y relevancia. Los registros cartográficos se presentan siempre por el lugar geográfico y la fecha (título uniforme) y el título formal:

I Ceuta. Fortificaciones. Planos. 1721. A Obra nueva hecha de seis dias en la altura de los colorados y playa 目 


\subsection{Descripción del material cartográfico}

Desde el listado, se puede acceder directamente a la ficha descriptiva pinchando en el enlace hipertextual del título (Figura 5). También se puede acceder a la imagen digitalizada pinchando en la miniatura que se presenta delante de cada título. La descripción utiliza como normas de contenido las RC y las AACR2, siguiendo en general los criterios de la Biblioteca Nacional (España) para este tipo de materiales.

\subsection{Formatos de visualización}

La ficha catalográfica aparece por defecto en formato "ficha" aunque se puede cambiar a otros formatos, como ISBD, MARC $21 \ldots$

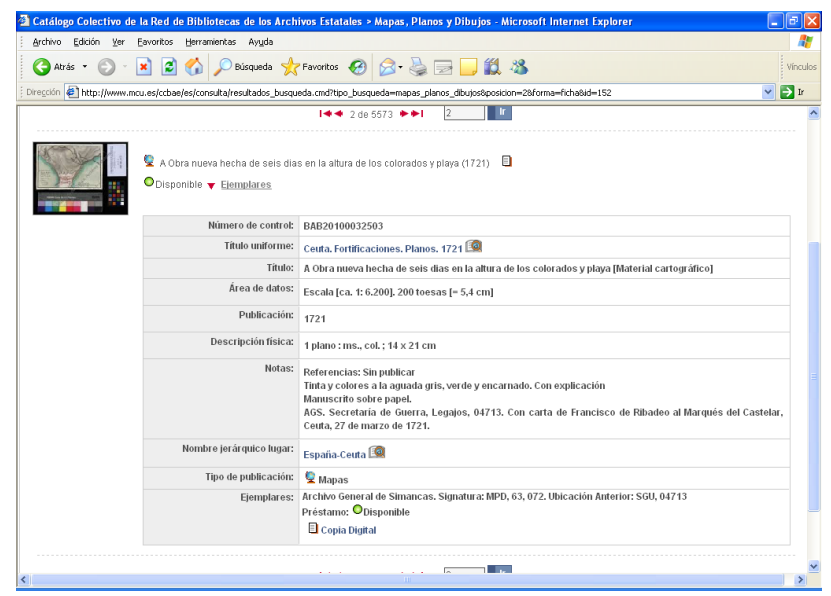

Figura 5. Visualización de un registro cartográfico

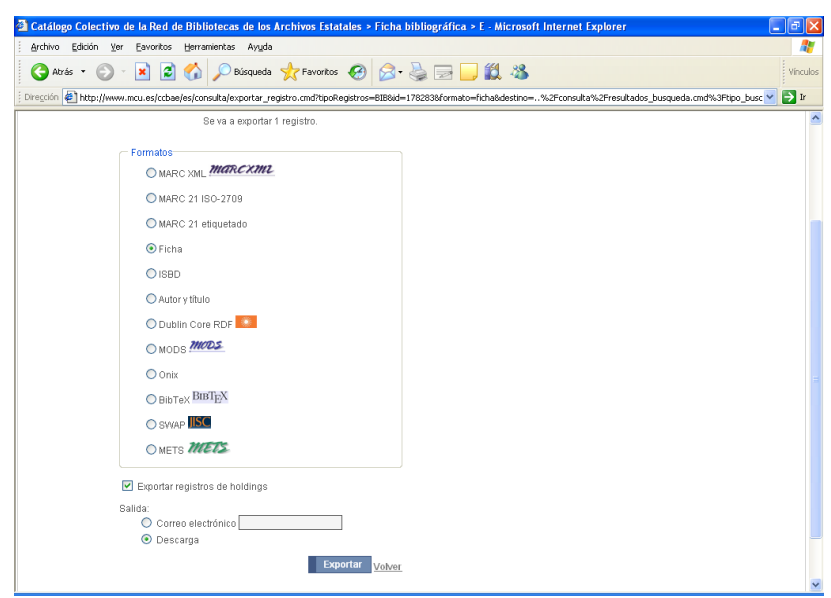

Figura 6. Pantalla de acceso a los formatos de exportación

\subsection{Exportación de los registros}

Otra de las posibilidades que lleva implícita la base de datos es la de poder exportar los registros en una gran cantidad de formatos, ya sean de texto o base de datos (MARC 21, Dublin
Core...). Esto facilita el manejo de la información a los usuarios de la colección (Figura 6). Pero no solo se puede exportar la descripción bibliográfica, sino también la propia imagen digitalizada.

\subsection{Visualización y descarga de las imágenes}

Se accede a la imagen a través de la miniatura que aparece en el listado de títulos. Las imágenes digitalizadas aparecen con una calidad de 150 dpi en ficheros jpg. La imagen lleva una marca de agua que es la que se utiliza en los Archivos Estatales (Figura 7).

El sistema permite rotar la imagen, hacer zoom sobre determinadas zonas, ver la imagen en formato $1: 1$, imprimirla y por último descargarla.

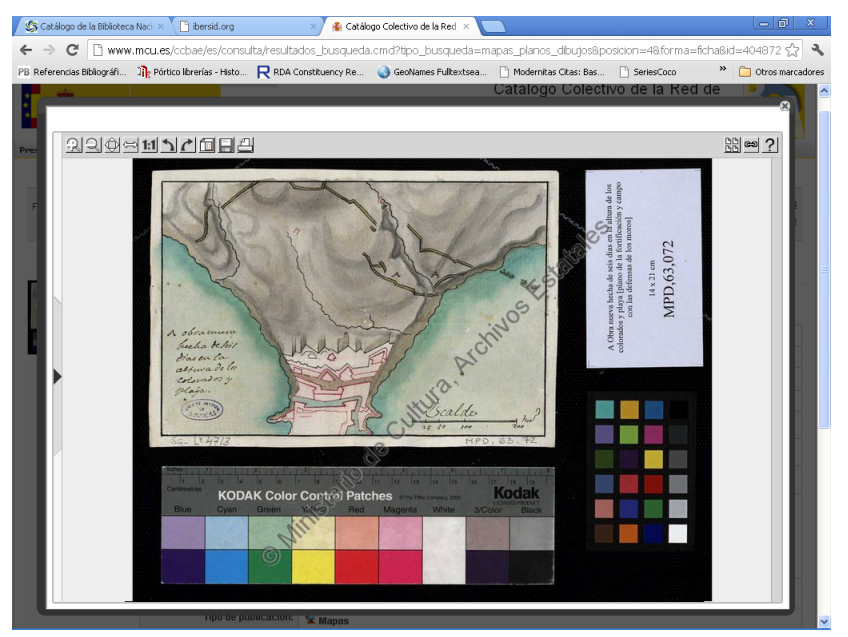

Figura 7. Visualización de la catalogación de un item cartográfico

\section{Nuevos proyectos}

El trabajo futuro se centra en dos nuevos proyectos, el de georreferenciación y el de publicación en las Infraestructuras de Datos Espaciales (IDE).

\subsection{Proyecto de georreferenciación}

El proceso de georreferenciación consiste en asignar coordenadas a un determinado punto de la imagen (píxel) (Roset y Ramos, 2011). Se asignan coordenadas geográficas al mapa, de forma que cada punto (píxel) pueda ser relacionado con uno de la superficie terrestre, facilitando que se puedan llevar a cabo medidas y comparaciones. Nuestro objetivo es ayudar al usuario en sus búsquedas de información dentro de nuestra colección cartográfica. Le damos las herramientas adecuadas para realizar estudios pormenorizados de la cartografía antigua. Por ejemplo, con las herramientas de transparencia 
se pueden intuir los errores del cartógrafo comprobando la mayor fiabilidad de las partes centrales de los mapas, comparando planos de diferentes escalas y creando nuestras propias colecciones (Fernandez Wyttenbach y Camacho, 2011)

No nos interesa una georreferenciación "exhaustiva", sino que, más bien, queremos aplicar la "básica", en la que el mapa antiguo no se vea distorsionado. Por todo esto, el proceso de localización geográfica no es tan preciso; y proporciona, en los casos más extremos, un valor aproximado de la ubicación de los mapas, basándose en los valores máximos y mínimos de las coordenadas de su envolvente geográfica.

Desde que se inauguró en el 2011 el Catálogo Colectivo de las Colecciones de Mapas, Planos y Dibujos de los Archivos Estatales, ya están disponibles en la red más de 7.000 documentos de la colección del Archivo General de Simancas. Los documentos cartográficos tienen la carencia de que no tienen geometadatos asociados.

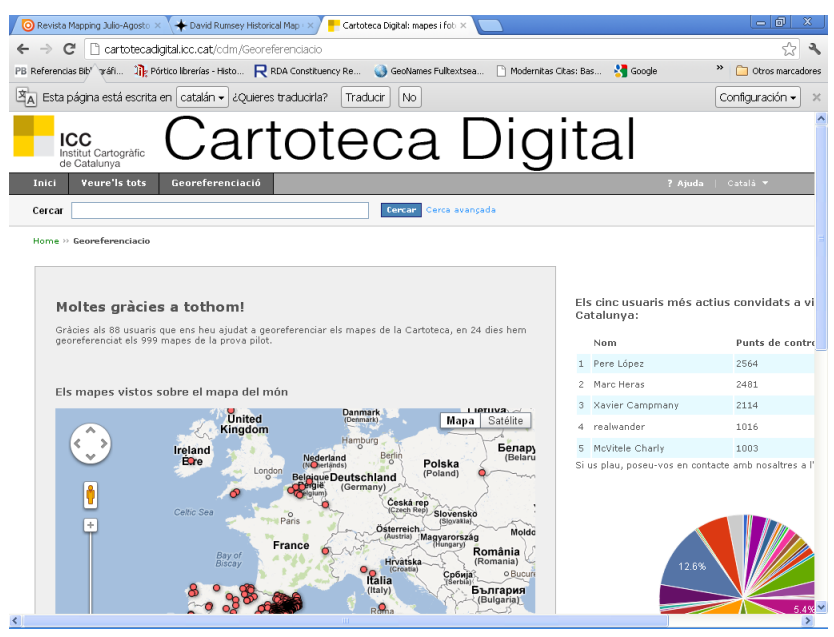

Figura 8. Página de la Cartoteca Digital del Institut Cartogràfic de Catalunya

Ya existen instituciones que han georeferenciado los materiales cartográficos para facilitar su visualización y para poner en marcha buscadores geográficos. También se han puesto en marcha proyectos colaborativos (Institut Cartogràphic de Catalunya, 2003-), en los que los propios usuarios han aportado información geográfica, permitiendo emprender proyectos sin destinar grandes cantidades de recursos (Figura 8).

No nos hemos decantado por un proyecto "colaborativo", por un lado, por el reducido número de documentos cartográficos, que no superan los 6.000 items; y, por otro, por la dificultad de georeferenciar cartografía antigua de los siglos XVI al
XVIII, que impide realizar un ajuste exacto de los puntos de control. Nos parece más pertinente para nuestra colección la aplicación desarrollada por la David Rumsey Historical Map Collection (Cartographic Associates, 2013). Esta permite al usuario varias posibilidades de visualización entre las que destaca las de Google Earth, en el visor del propio buscador o lanzando el programa en pantalla aparte. La idea, siguiendo el mismo criterio que la colección Rumsey, es comenzar con una selección de cartografía, pero con la intención de que el visor sirva como buscador de toda la colección (Figura 9).

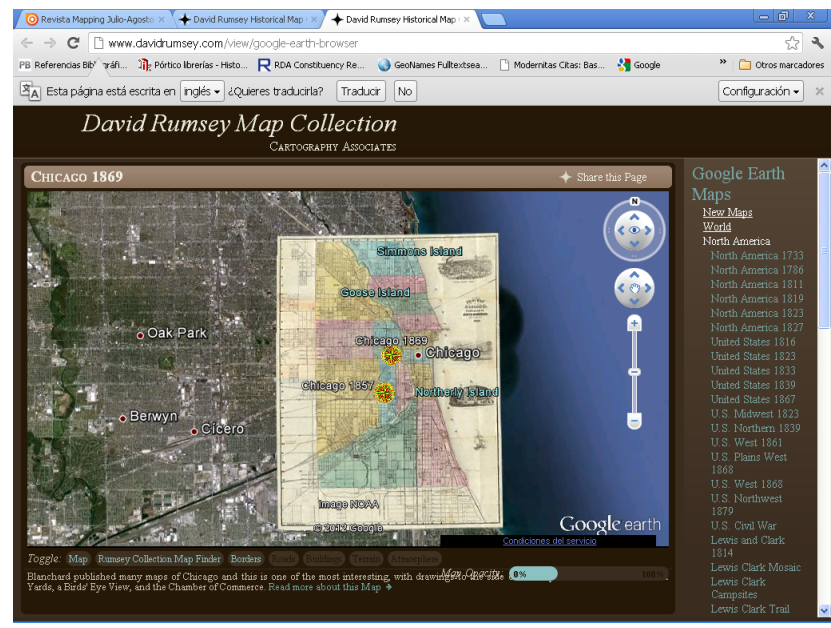

Figura 9. Pagina principal de la David Rumsey Map Collection

El archivo digital del mapa (raster), en nuestro caso es una imagen en formato jpg y $150 \mathrm{dpi}$ de resolución, que se encuentra en nuestro repositorio OAl. Para georeferenciar utilizaríamos Google Earth, que proporciona una interfaz simple y gratuita para realizar el proceso (Figura 10).

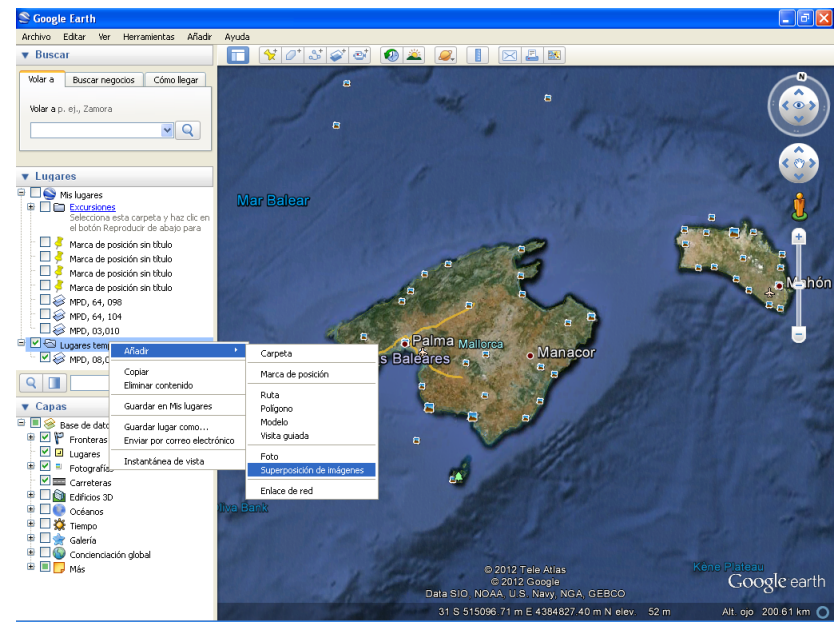

Figura 10. Google Earth 
Desde "Lugares temporales" en Google Earth damos el botón "Añadir" y "Superposición de imágenes". Le damos un título y enlazamos la imagen digital que se encuentra en nuestro repositorio OAI. Nos aparece la imagen superpuesta sobre la cartografía con las herramientas para adaptar la imagen a la cartografía real. Cuando se logra que coincidan, el sistema da una ubicación de la cuadrícula (norte, sur, este. Oeste y rotación). En este momento hemos georeferenciado el mapa digital. Ahora tenemos que guardar los datos "Guardar lugar como" en la que Google Earth crea un archivo con extensión "kml". Es el archivo de la georeferenciación que guarda los puntos de control (coordenadas) y el archivo georreferenciado. Es el archivo que va a servir de enlace entre nuestra base y el visor (Google Earth).

Actualmente la idea no ha pasado de la fase de diseño, ya que la Subdirección General de Archivos todavía no se ha implicado en nuestro proyecto. Nuestro sistema de gestión bibliotecaria, Digibib, sobre el que se asienta el proyecto, nos permite enlazar ficheros $\mathrm{kml}$, por lo que podríamos georreferenciar y visualizar en Google Earth nuestros planos sin costo alguno. Cada registro llevaría un enlace que "lanzaría" automáticamente el visor. Lo que ya sería más complejo es intentar que nuestra propia web albergara el buscador geográfico, como lo hace la Colección Rumsey, ya que nos obligaría a modificar su diseño.

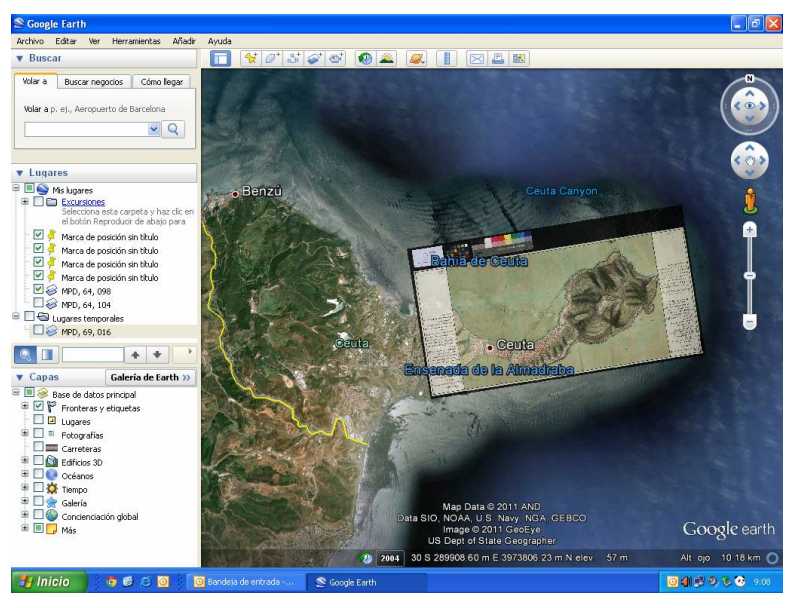

Figura 11. Google Earth. Visualización de un plano georeferenciado

Nuestro sistema además permitiría que, al enlazar el fichero $\mathrm{kml}$ a nuestra base de datos, el sistema extrajera la localización geográfica (coordenadas GPS) y a partir de este momento formaran parte del propio registro descriptivo. Esto nos va a permitir poder acceder a otro nivel de difusión de nuestra colección, al formar parte de los portales de acceso a la información geográfica desarrollados con tecnología IDE (Figura 11).

5.2. Publicación del Patrimonio cartográfico histórico en las Infraestructuras de Datos espaciales (IDE): Portales de acceso a la información geográfica

En Junio del 2008 se creó el Grupo de Trabajo Interdisciplinar Patrimonio Cartográfico en las IDEE. Su fin último era promover la publicación de documentación geográfica de carácter histórico por medio de las IDE.

Dentro de los objetivos específicos del grupo está la interoperabilidad entre los formatos MARC e ISO 19115 para acometer la publicación de cartografía histórica en Internet vía IDE, y la construcción de una pasarela lógica y de las herramientas informáticas correspondientes que posibiliten la interoperabilidad entre ambos sistemas.

En octubre de 2008 se invitó al Archivo General de Simancas a formar parte de este grupo de trabajo.

La información geográfica posee una serie de características y particularidades que es necesario reflejar a través de registros de metadatos, aportando así la información que permite a los usuarios comprender y acceder mejor a los datos en cuestión. La mayor parte de la catalogación de información geográfica moderna (centros productores de cartografía) se realiza en perfiles ISO 19115. Para que los fondos de cartotecas, bibliotecas y archivos (cartografía antigua) (4), descritos en formato Marc (ISO 2709), puedan participar en los desarrollos modernos de publicación de información geográfica, se ha definido una pasarela que relaciona ambos formatos ISO: el MARC y el ISO 19115.

El objetivo del grupo se centra en realizar un mapeo entre los campos de ambos formatos. Actualmente la Norma ISO 19115:2003 Información Geográfica - Metadatos es la referencia obligada a la hora de generar metadatos de datos geográficos.

Para nosotros resulta indispensable poder acceder a nuevos canales de difusión de nuestra información. Las IDE son infraestructuras que establecen un conjunto de tecnologías, políticas y disposiciones institucionales que facilitan el acceso y explotación de datos espaciales. Contienen además servicios de catálogo para acceder a la información geográfica de los centros productores de cartografía. Con la implementación de la pasarela podremos difundir el contenido de nuestros fondos en este tipo de infraes- 
tructuras, con todo lo que ello lleva consigo de mayor difusión y visualización de la colección. La cartografía antigua aparecería como una nueva capa dentro de los nuevos geoportales IDE.

Todos aquellos mapas georreferenciados con el proyecto "Google Earth" podrían ser volcarlos en cualquier geoportal con formato ISO 19115.

\section{Conclusiones}

La publicación en la web del Catálogo de Mapas, Planos y Dibujos del Archivo General de Simancas ha sido la primera etapa en el trabajo de puesta en marcha del Catálogo Colectivo de Colecciones de Mapas, Planos y Dibujos de los Archivos Estatales.

Podemos decir que el trabajo ha dado sus frutos y ha permitido la difusión de la colección del Archivo General de Simancas en todo el mundo, facilitando el acceso no solo a la descripción sino también a la digitalización de todos sus fondos.

Antes de 2010, el acceso a la colección de mapas y planos, sólo se podía realizar de forma informática en el propio archivo, donde se podía consultar la base de datos local; $y$, fuera de él, a través de los instrumentos de descripción impresos. Es en 2011 cuando se produce la verdadera revolución en el acceso a la información. El servidor web donde está alojada la colección permitió acceder desde cualquier parte del mundo y desde cualquier buscador (no es necesario entrar directamente a la colección para realizar una búsqueda). Google te lleva directamente a la documentación contenida en la colección. Ya no es necesario que el usuario conozca nuestra página y busque directamente en nuestra base de datos. Es el propio buscador el que localiza cualquier documento.

Este aumento de difusión y visibilidad se ha debido a la utilización de una normalización tanto en la estructura de datos (MARC 21), como en la de contenidos (ISBD, AACR2, RC) y en la propia página web, a la que se ha dotado de un repositorio digital con tecnología OAI$\mathrm{MPH}$. Esto permite que nuestro repositorio sea "recolectado" por otras bases de datos como Europeana o Hispana, lo que mejora aún más el acceso y la difusión de nuestros fondos.

Si los fondos de Simancas ya estaban al públi$\mathrm{co}$, ahora lo que se ha conseguido es aumentar exponencialmente su visibilidad. La web permite llegar desde todo el mundo a los documentos de nuestra colección lo que ha dado lugar a un gran aumento en el número de visitas. Según las estadísticas del Ministerio de Cultura, en el
2011 se visitaron, dentro de la Colección de Mapas, Planos y Dibujos del AGS, 38.144 páginas, con 1.699 accesos. En el periodo eneroagosto del 2012 el número de visitas había aumentado exponencialmente con 85.764 páginas consultadas y con 2.461 accesos.

Esta revolución tecnológica no sólo ha cambiado el acceso a la información sino también la relación del archivo con sus usuarios.

- Cualquier error detectado en la descripción, después de comprobado, es corregido inmediatamente. El usuario a través del "Contacte" del servidor web puede conectar directamente con el Archivo y comunicar cualquier detalle relacionado con la descripción. También puede informar de cualquier error en la visualización de los registros o cualquier otro tipo de problemas en la base de datos.

- El usuario puede colaborar en la descripción. Cualquier propuesta de modificación tiene que verse avalada por un artículo especializado que la corrobore. Se detallará siempre la procedencia de la información, insertando la referencia bibliográfica en la propia descripción.

- La propia estructura del servidor web permite que usuarios inserten (mediante el enlace persistente) toda la información del catálogo en sus propios trabajos técnicos sobre cartografía editados en la web. Es una nueva forma de publicar información cartográfica que se ve facilitada por las herramientas de las que dispone nuestro sistema.

Blogs como el de "Alta Mar" son un ejemplo de lo que estos nuevos catálogos permiten a los usuarios (Figura 12) (Fabián, 2013).

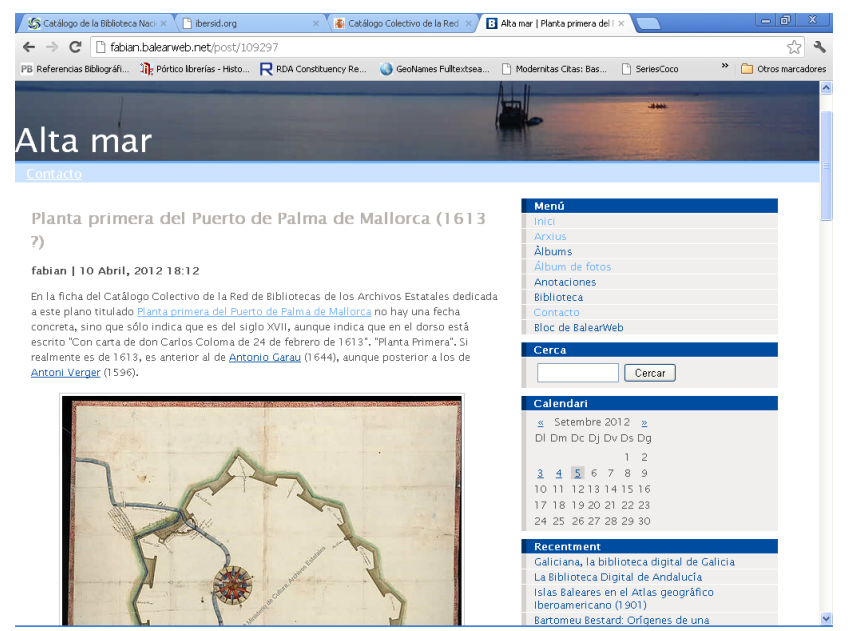

Figura 12. Blog "Alta Mar" 
Con el servidor web, por lo tanto, han cambiado los criterios de descripción, pasándose de catálogos rígidos y sin cambios a lo largo del tiempo a descripciones más flexibles y cambiantes. Esta flexibilidad da lugar a una mayor riqueza de la descripción.

\section{Notas}

(1) Catálogo de autoridades es el establecido por el centro catalogador con los encabezamientos aceptados de personas, entidades u obras, así como sus posibles variantes (Martínez de Sousa, 2004).

(2) EI MARC es el formato de intercambio por excelencia para el mundo bibliotecario. Normaliza el intercambio de información bibliográfica en soporte legible por máquina (Ríos Hilario, 2003).

(3) El Portal de Archivos Españoles es un proyecto del Ministerio de Educación, Cultura y Deporte destinado a la difusión en Internet del Patrimonio Histórico Documental Español conservado en su red de centros. PARES ofrece un acceso libre y gratuito, no solo al investigador, sino también a cualquier ciudadano interesado en acceder a los documentos con imágenes digitalizadas de los Archivos Españoles.

(4) Patrimonio Cartográfico son todos aquellos documentos que contienen información geográfica, que ya no cumplen con el propósito para las que fueron creados y que son susceptibles de reutilización.

\section{Referencias}

Anglo-American cataloguing rules (2002) / prepared under the direction of the Joint Steering Committee for Revision of AACR, a committee of the American Library Association ... [et al.]. 2nd ed., 2002 revision. Ottawa (Canadá); Chicago (Estados Unidos): Canadian Library Association: American Library Association, 2002-

Cartographic Associates (2013). David Rumsey Historical Map Collection (2013). http://www.davidrumsey.com (2012-08-13).

El patrimonio cartográfico en las infraestructuras de datos espaciales (2012) // Revista Catalana de Geografía. IV època. XV:41 (desembre 2010). http://www.rcg.cat/arti cles. php?id=199

Fabián (2013). Alta Mar (Blog). http://fabian.balearweb.net/ (2012-08-13)
Fernandez Wyttenbach, Alberto; Camacho, Elena (2011.) La Georreferenciación: una propuesta metodológica. Madrid, 2011.

Institut Cartogràphic de Catalunya (2003-). Cartoteca digital. http://cartotecadigital.icc.cat/cdm/Georeferenciacio (2012-08-13).

International Standard Bibliographic Description (ISBD) (2007) / recommended by the ISBD Review Group ; approved by the Standing Committee of the IFLA Cataloguing Section. Preliminary consolidated ed. München : Saur, 2007.

ISAD(G): norma internacional general de descripción archivística / [versión española de Asunción de Navascués Benlloch ; en colaboración con María Dolores Carnicer Arribas, Blanca Desantes Fernández y Guadalupe Moreno López]. $2^{a}$ ed. [Madrid]: Dirección General de los Archivos Estatales, [2000].

Library of Congress (s. d.). MARC 21. Washington: Library of Congress. http://www.loc.gov/marc/marcspa.html

Martínez de Sousa, José (2004). Diccionario de bibliología y ciencias afines: terminología relativa a archivística, artes e industrias gráficas... $3^{\mathrm{a}}$ ed. muy aum. Gijón: Trea, 2004.

Ministerio de Educación, Cultura y Deporte (s. a.). Catálogo Colectivo de la Colección de Mapas, Planos y Dibujos de los Archivos Estatales. http://www.mcu.es/ccbae/ es/mapas/principal.cmd (2012-08-13).

Reglas de catalogación (2000). Ed. nuevamente rev. Madrid: Ministerio de Educación y Cultura, Centro de Publicaciones, Boletín Oficial del Estado, 1999 (imp. 2000).

Resource description \& access (RDA) / developed in a collaborative process led by the Joint Steering Committee for Development of RDA (JSC). Chicago : American Library Association, 2011.

Ríos Hilario, Ana Belén (2003). Nuevos horizontes en el análisis de los registros y la normativa bibliográfica. [Gijón]: Trea, [2003].

Roset, Rafael ; Ramos, Noelia (2012). Georeferenciación de mapas antiguos con herramientas de código abierto: un caso práctico. // Mapping. 1 (julio-agosto 2011). http://issuu.com/mappinglatino/docs/mapping_ca4-2011.

Society of American Archivists (2004). Describing archives: a content standard. Chicago: The Society of American Archivist, 2004.

Fecha de envío: 2012-09-14.

Fecha de aceptación: 2013-06-14. 
